\title{
Effect of heat and relative humidity treatment on $\gamma$-aminobutyric acid accumulation, other micronutrients contents, antioxidant activities and physicochemical properties of mung bean (Vigna radiata $L$.
}

\author{
Yuling Ma, ${ }^{1,3}$ (D) Litao Tong, ${ }^{1}$ (D) Shanshan Wang, ${ }^{1}$ Tingyu Liu, ${ }^{1}$ Lili Wang, ${ }^{1}$ Liya Liu, ${ }^{1}$ Xianrong Zhou, ${ }^{1}$ \\ Sumei Zhou ${ }^{2 *} \&$ Christophe Blecker ${ }^{3 *}$ \\ 1 Institute of Food Science and Technology, Chinese Academy of Agricultural Sciences, Haidian District, Beijing, China \\ 2 Beijing Advanced Innovation Center for Food Nutrition and Human Health, School of Food and Health, Beijing Technology \& Business \\ University (BTBU), Haidian District, Beijing, China \\ 3 Department of Food Science and Formulation, Gembloux Agro-Bio Tech, Université de Liège, Gembloux, Belgium
}

(Received 31 August 2021; Accepted in revised form 3 November 2021)

\begin{abstract}
Summary A novel approach to heat and relative humidity ( $\mathrm{HRH}, 65-75^{\circ} \mathrm{C}, 98 \% \mathrm{RH}$ ) treatment was used to enhance $\gamma$-aminobutyric acid (GABA) of mung bean with a low moisture (12-20\%) within several hours (4-6 h). Meanwhile, the changes in micronutrients, antioxidant activities and physicochemical properties were also evaluated. Results showed that the GABA content was significantly accumulated, increasing from 1.73 to $109.78 \mathrm{mg} 100 \mathrm{~g}^{-1}$ dry weight (DW) under the conditions of $16.72 \%$ moisture, $68.97{ }^{\circ} \mathrm{C}$, $98 \% \mathrm{RH}$ for $5.34 \mathrm{~h}$. Meanwhile, the amino acids, including aromatic (tyrosine and phenylalanine), sulphur-containing (methionine and cystine) and branched-chain amino acids (leucine, isoleucine and valine), were significantly increased $(P<0.05)$. Although $\mathrm{HRH}$ treatment decreased the total anthocyanin content of mung bean, the total phenolic, vitexin and isovitexin contents, and antioxidant activities were significantly increased $(P<0.05)$. Furthermore, HRH treatment caused the wrinkled structure of mung bean coat, increased the paste viscosity of mung bean flour and decreased the time of complete gelatinisation of starch in mung bean by one third during cooking. These results suggested that HRH treatment could effectively elevate the above functional components, especially GABA, improve the antioxidant activities, pasting and cooking properties of mung bean.
\end{abstract}

Keywords Functional properties, Heat and relative humidity treatment, mung bean, physicochemical characteristics, $\gamma$-aminobutyric acid.

\section{Introduction}

$\gamma$-Aminobutyric acid (GABA), a non-proteinogenic amino acid, has various health benefits, such as antihypertensive, anti-diabetic and neuroprotective effects (Diez-Gutiérrez et al., 2020). According to the previous studies, GABA is present in small amounts in grains and legumes, which are consumed in the human daily diet (Chua et al., 2019). Multitudinous methods have been used to increase the GABA contents in grains and legumes, such as soaking, germination and fermentation. However, these methods commonly consumed a lot of water and time (generally more than $24 \mathrm{~h}$ ), and the shape and flavour were also changed

*Correspondent: Emails: zhousumei1001@163.com, (S. Zhou); and christophe.blecker@ulg.ac.be, (C. Blecker) compared with the non-processed materials (Komatsuzaki et al., 2007; Liao et al., 2013). Heat and relative humidity ( $\left.\mathrm{HRH}, \quad 60-80{ }^{\circ} \mathrm{C}, 80-98 \% \mathrm{RH}\right)$ treatment may be a potential method to address these challenges (Fukumori et al., 2013). Studies have shown that the GABA content of rice with insufficient moisture $(16 \sim 18.5 \%)$ was increased significantly, from 1.5 to $17.8 \mathrm{mg} 100 \mathrm{~g}^{-1}$ DW under $\mathrm{HRH}$ treatment $\left(50{ }^{\circ} \mathrm{C}\right.$ and $90 \% \mathrm{RH}$ or more) within several hours (Fukumori et al., 2013). This method can not only reduce the cost of hydration and dehydration during processing, such as soaking and germination, but also avoid the changes of rice taste, which make it can be consumed like the native rice.

Mung bean (Vigna radiata L.) has been recommended as an excellent nutritional and functional 
legume to prevent many chronic degenerative diseases due to its health benefits (Ganesan \& Xu, 2018). It is also popular with vegetarian and celiac disease populations because of high protein content and gluten-free (Zhu et al., 2018). At present, soaking, germination and fermentation under different conditions have been shown to increase the GABA content of mung bean, as well as other nutritional components (Nikmaram et al., 2017). Moreover, these GABA-enriched mung beans have been applied in the production of functional products (Wu et al., 2015; Liu et al., 2018). However, the studies about the effect of different HRH treatment conditions on GABA and other chemical components contents of mung bean were deficient, thus restricting its application. Furthermore, physicochemical properties of mung bean and flour, as crucial characteristics of processing and utilisation, such as colour, thermal and pasting properties, may also be modified under HRH treatment. Liu et al. (2018) reported that although mung bean sprout had high nutritional and functional properties, the brightness and pasting viscosity decreased with the increase of germination time, which eventually affected the quality of mung bean noodles. In addition, the thermal properties of mung bean starch were increased significantly under heat-moisture treatment (Li et al., 2011a), while its pasting properties had a significant decrease under repeated and continuous dry heat treatments (Liang et al., 2020). It has been illustrated that viscosity, gelatinisation and retrogradation of starch played a vital role in the qualities of noodles and 'rigid' structure of gluten-free pasta (Li et al., 2012; Marti \& Pagani, 2013). However, mung bean, as a gluten-free and starch-enriched food, its thermal and pasting properties under HRH treatment have not been explored. Notably, the hard coat of mung bean made it difficult to cook, which limited its consumption, especially for people with the accelerating pace of life. HRH treatment might address this problem in consideration of the changes in the structure of mung bean coat during hydration and dehydration. However, no reports focussed on cooking properties of mung bean.

Therefore, the purposes of this study are 1) to explore the effect of different HRH treatment conditions on GABA content of mung bean, and optimise HRH treatment conditions for obtaining a highest GABA content; 2) to study the changes of other micronutrients, antioxidant activities and physicochemical properties of mung bean after HRH treatment; 3) to explore the starch gelatinisation degree of native and $\mathrm{HRH}$-treated mung bean with different cooking time. Our study focussed on the comprehensive understanding about the effects of HRH treatment on mung bean, eventually promoting the development of GABA-enriched mung bean products.

\section{Materials and methods}

\section{Materials and reagents}

Mung bean (Jilv No.9) was obtained from Sandou Food Co., Ltd, Hebei province, China. The GABA, gallic acid (GA), Folin-Ciocalteu reagent, 6-hydroxy2,5,7,8- tetramethylchroman-2-carboxylic acid (Trolox), DPPH (1,1-diphenyl-2-picrylhydrazyl) and ABTS (2,2'-Azino-bis 3 ethylbenzothiazoline-6-sulphonic acid) were all purchased from Sigma-Aldrich Chemical Co. Ltd (St. Louis, MO, USA). Mixed free amino acid standards were provided by Wako Pure Chemical Industries (Osaka, Japan). Dabsyl chloride was purchased from Med Chem Express (MCE, America). All the chemicals were of analytical and/or HPLC grade.

\section{HRH treatment}

According to the method of Fukumori et al. (2013), Supplement Fig. 1 shows the HRH-treated mung bean preparation flow sheet. Briefly, in the tempering stage, $50 \mathrm{~g}$ of mung bean was washed and packed in a sealed vessel to absorb water under different tempering conditions (tempering moisture, temperature and time) by manually shaking. In the $\mathrm{HRH}$ treatment stage, the tempered mung beans were treated under different HRH conditions (HRH treatment temperature, relative humidity and time) in a temperature and humidity test chamber (KW-TH-49T, Dongguan KOWIN Testing Equipment Co., Ltd, Guangdong, China). After that, the samples were freeze-dried and were pulverised to flour by a laboratory mill (CT 410 Cyclotec TM, FOSS Scino Co. Ltd, Suzhou, China). Then, these samples were sealed in plastic bags with some desiccant inside and stored at $4{ }^{\circ} \mathrm{C}$ for further analysis.

\section{Optimisation of HRH treatment conditions for GABA accumulation}

The effects of HRH treatment conditions on GABA accumulation were determined by single-factor tests (Supplement Fig. 2). Then, the GABA content was used as the response value for response surface methodology (RSM). A Box-Behnken design with three independent factors (A, tempering moisture; B, $\mathrm{HRH}$ treatment temperature; $\mathrm{C}, \mathrm{HRH}$ treatment time) at three variation levels was performed. According to the ranges of the value of factors $\mathrm{A}, \mathrm{B}$ and $\mathrm{C}, 17$ experiments were employed, which include 12 factorial points and 5 replicates of the central point, which were used to optimise the GABA content (Table 1). The GABA content $(Y)$ was the response value. DesignExpert software (Trial Version 11.1.0.1, Stat-Ease Inc., Minneapolis, Minnesota, USA) was used to analyse 
Table 1 Response surface design for GABA optimisation in mung bean under $\mathrm{HRH}$ treatment and the observed response

\begin{tabular}{|c|c|c|c|c|}
\hline \multirow[b]{2}{*}{ Run } & \multicolumn{3}{|c|}{ Independent variables } & \multirow{2}{*}{$\begin{array}{l}\text { Response } \\
\text { GABA (mg/100 g, DW) }\end{array}$} \\
\hline & $A(\%)$ & B $\left({ }^{\circ} \mathbf{C}\right)$ & C (h) & \\
\hline 1 & 12 & 65 & 5 & $74.58 \pm 1.84$ \\
\hline 2 & 20 & 65 & 5 & $95.75 \pm 2.46$ \\
\hline 3 & 12 & 75 & 5 & $69.98 \pm 2.1$ \\
\hline 4 & 20 & 75 & 5 & $74.56 \pm 2.18$ \\
\hline 5 & 12 & 70 & 4 & $89.51 \pm 1.88$ \\
\hline 6 & 20 & 70 & 4 & $93.52 \pm 1.84$ \\
\hline 7 & 12 & 70 & 6 & $95.37 \pm 2.62$ \\
\hline 8 & 20 & 70 & 6 & $95.60 \pm 2.6$ \\
\hline 9 & 16 & 65 & 4 & $86.58 \pm 1.19$ \\
\hline 10 & 16 & 75 & 4 & $79.59 \pm 1.48$ \\
\hline 11 & 16 & 65 & 6 & $100.15 \pm 2.17$ \\
\hline 12 & 16 & 75 & 6 & $80.64 \pm 0.95$ \\
\hline 13 & 16 & 70 & 5 & $109.46 \pm 2.43$ \\
\hline 14 & 16 & 70 & 5 & $112.28 \pm 2.98$ \\
\hline 15 & 16 & 70 & 5 & $105.97 \pm 2.36$ \\
\hline 16 & 16 & 70 & 5 & $111.14 \pm 2.28$ \\
\hline 17 & 16 & 70 & 5 & $109.89 \pm 2.42$ \\
\hline
\end{tabular}

the experimental data. Then, the data were fitted to a second-order polynomial model, and the regression coefficients were obtained. The fitted quadratic mode for GABA (Y) of HRH-treated mung bean was shown in Eq. (1):

$$
\begin{gathered}
\mathrm{Y}(\mathrm{GABA}, \mathrm{g} / 100 \mathrm{~g}, \mathrm{DW})=-4317.05125+40.40519 \mathrm{~A} \\
+111.90415 \mathrm{~B}+86.79750 \mathrm{C}-0.207375 \mathrm{AB} \\
-0236250 \mathrm{AC}-0.526000 \mathrm{BC}-0.742828 \mathrm{~A}^{2} \\
+0.765810 \mathrm{~B}^{2}+4.36275 \mathrm{C}^{2}
\end{gathered}
$$

Where $\mathrm{Y}$ is the response value of GABA; $\mathrm{A}, \mathrm{B}$ and $\mathrm{C}$ are the independent variable of tempering moisture, $\mathrm{HRH}$ treatment temperature and time respectively. Based on the optimised conditions, HRH-treated mung beans were dried, milled and stored as above methods, then were used for the determination of other micronutrients, antioxidant activities and physicochemical properties.

\section{GABA content determination}

The GABA content was analysed by HPLC as described previously (Ma et al., 2021). In detail, mung bean flour $(1.0 \mathrm{~g})$ was mixed with $70 \%$ ethanol $(10 \mathrm{~mL})$ at room temperature for $30 \mathrm{~min}$. Then, the mixture was centrifuged at $11000 \mathrm{~g}, 25^{\circ} \mathrm{C}$ for $10 \mathrm{~min}$. Samples were extracted in triplicate. Then, all of the supernatant layers was mixed. Subsequently, $1.0 \mathrm{~mL}$ of the mixed supernatant, $0.2 \mathrm{~mL}$ of $\mathrm{NaHCO}_{3}(0.4 \mathrm{~g}$, in $10 \mathrm{~mL}$ water) and $0.4 \mathrm{~mL}$ of dabsyl chloride (20 mg, in $10 \mathrm{~mL}$ acetonitrile) were mixed and incubated at $70{ }^{\circ} \mathrm{C}$ for $20 \mathrm{~min}$. Then, the GABA content was determined using Agilent 1260 HPLC (Agilent Technologies Inc., USA) with a ZORBAX SB-C18 column $(5 \mu \mathrm{m}), 4.6 \times 250 \mathrm{~mm}$ i.d. Mobile Phase A and $\mathrm{B}$ was sodium acetate buffer solution $(50 \mathrm{mM}$, $69 \%$ ) and acetonitrile (31\%), respectively. HPLC was run at $1.0 \mathrm{~mL} \mathrm{~min}{ }^{-1}$ flow rate and $436 \mathrm{~nm}$ wavelength.

\section{Free amino acids determination}

Free amino acids (FAAs), including methionine (Met), isoleucine (Ile), leucine (Leu), valine (Val), phenylalanine (Phe), threonine (Thr), lysine (Lys), tyrosine (Tyr), histidine (His), cystine (Cys), arginine (Arg), taurine (Tau), ornithine (Orn), aspartic acid (Asp), glycine (Gly), serine (Ser), hydroxyproline (Hypro), alanine (Ala) and glutamic acid (Glu), were measured according to the method as described previously (Zhao et al., 2017). Mung bean flour $(0.5 \mathrm{~g})$ and $0.1 \mathrm{M} \mathrm{HCl}$ $(5.0 \mathrm{~mL})$ were mixed. Then, the mixture was sonicated for $10 \mathrm{~min}$ at room temperature and was centrifuged at $4193 \mathrm{~g}$ for $15 \mathrm{~min}$ at $25^{\circ} \mathrm{C}$. Afterwards, the obtained supernatant was adjusted to $5.0 \mathrm{~mL}$. Then, $1.0 \mathrm{~mL}$ of supernatant was mixed with $1.0 \mathrm{~mL}$ of $8 \%$ sulphosalicylic acid to purify the FAAs. After centrifugation at $16770 \mathrm{~g}$ for $15 \mathrm{~min}$ at $25^{\circ} \mathrm{C}, 1.0 \mathrm{~mL}$ of supernatant was dried by using flushing nitrogen. Then, $1.0 \mathrm{~mL}$ of $0.02 \mathrm{M} \mathrm{HCl}$ was used for reconstitution solution, and the reconstituted solution was filtered by using a $0.45 \mu \mathrm{m}$ filter membrane. Subsequently, the FAAs were analysed using an amino acid analyzer (L-8800, Hitachi, Japan).

\section{Phytochemical compounds determination}

The extraction of phytochemical compounds of mung bean was carried out based on the previous method with some modifications (Yao et al., 2011). $2.0 \mathrm{~g}$ of mung bean flour was extracted with $20 \mathrm{~mL}$ of $80 \%$ methanol-water and acidified methanol-water (v/v), respectively. The mixture was centrifuged at $4500 \mathrm{~g}$ for 10 min after shaking for $2 \mathrm{~h}$. The extraction was conducted in triplicate. Then, all the supernatant were collected and evaporated at $45{ }^{\circ} \mathrm{C}$ to less than $5.0 \mathrm{~mL}$. Finally, the concentrated extracting solution was diluted to $10 \mathrm{~mL}$ with extraction solvent. The extracts were stored at $-20^{\circ} \mathrm{C}$ in the dark until analysis.

Total phenolic content (TPC) was measured using Folin-Ciocalteu method according to Yao et al. (2010). Briefly, $1.0 \mathrm{~mL}$ of $1 \mathrm{~N}$ Folin-Ciocalteu was thoroughly mixed with $1.0 \mathrm{~mL}$ of methanol-water extracts or GA solution, and then $3.0 \mathrm{~mL}$ of $\mathrm{Na}_{2} \mathrm{CO}_{3}$ $(10 \mathrm{~g}$, in $100 \mathrm{~mL}$ distilled water) was added into the 
above mixture. Then, the mixture was placed at room temperature in the dark for $60 \mathrm{~min}$ before the absorbance was measured at $765 \mathrm{~nm}$. The result was expressed as mg GA equivalents (GAE) per gram dry sample.

Total anthocyanins content (TAC) determination was performed according to Hosseinian et al. (2008) with some modifications. The absorbance of acidified methanol-water extract was measured at $520 \mathrm{~nm}$ and at $700 \mathrm{~nm}$ in buffers at $\mathrm{pH} 1.0$ and 4.5 , respectively. TAC of extracts $\left(\mathrm{mg} \mathrm{L}^{-1}\right)=\{[(\mathrm{A} 510-\mathrm{A} 700) \mathrm{pH}$ $\left.1.0-(\mathrm{A} 510-\mathrm{A} 700) \quad \mathrm{pH} \quad 4.5] \times \mathrm{MW} \times \mathrm{DF} \times 10^{3}\right\} /$ $(\varepsilon \times 1)$, where MW is the molecular weight $\left(\mathrm{g} \mathrm{mol}^{-1}\right)$ $=449.2 \mathrm{~g} \mathrm{~mol}^{-1}$ for cyanidin-3-glucoside (Cy-3-glc), $\mathrm{DF}$ is the dilution, and $\varepsilon$ is the extinction coefficient $\left(\mathrm{L} \times \mathrm{cm}^{-1} \times \mathrm{mol}^{-1}\right)=26,900$ for $\mathrm{Cy}-3$-glc. The result was expressed as Cy-3-glc equivalents per gram dry sample.

Vitexin and isovitexin were measured according to Yao et al. (2011).

\section{Antioxidant activities determination}

The DPPH and ABTS radical scavenging activity of methanol-water extract were estimated according to the method of Yao et al. (2010). For DPPH radical scavenging activity, $1.0 \mathrm{~mL}$ of DPPH solution $(8.0 \mathrm{mg}$ DPPH powder was dissolved with $100 \mathrm{~mL} 80 \%$ methanol) was added to $1.0 \mathrm{~mL}$ of extract or Trolox solution. The mixture was placed at room temperature in dark for $30 \mathrm{~min}$ before the absorbance was measured at $517 \mathrm{~nm}$. ABTS. ${ }^{+}$working solution was prepared by reacting ABTS solution $(7 \mu \mathrm{M}$ ABTS, in redistilled water) with $2.45 \mathrm{mM} \mathrm{K} \mathrm{K}_{2} \mathrm{~S}_{8}$ and kept at room temperature in the dark for $16 \mathrm{~h}$, and then diluted with distilled water to an absorbance of 0.70 $( \pm 0.02)$ at $734 \mathrm{~nm}$. For ABTS radical scavenging activity, $50.0 \mu \mathrm{L}$ extracts or Trolox solution and $3.0 \mathrm{~mL}$ ABTS. ${ }^{+}$working solution were mixed and put at room temperature in dark for $20 \mathrm{~min}$ before the absorbance was measured at $734 \mathrm{~nm}$. The results were expressed as Trolox equivalents (TE) per gram dry sample.

The ferric reducing antioxidant power (FRAP) assay was conducted according to Chen et al. (2014). The FRAP working solution was prepared by mixing $300 \mathrm{mM}$ pH3.6 acetate buffer $\left(3.1 \mathrm{~g} \mathrm{C}_{2} \mathrm{H}_{3} \mathrm{NaO}_{2} .3 \mathrm{H}_{2} \mathrm{O}\right.$ and $\left.16 \mathrm{~mL} \mathrm{C}_{2} \mathrm{H}_{4} \mathrm{O}_{2}\right), 10 \mathrm{mM}$ IPTZ (2,4,6-tripyridyl-striazine, $40 \mathrm{mM} \mathrm{HCl}$ ) and $20 \mathrm{mM} \mathrm{FeCl} 3.6 \mathrm{H}_{2} \mathrm{O}$ solution in a ratio of $10: 1: 1$. Then, $6.0 \mathrm{~mL}$ of FRAP working solution, $0.2 \mathrm{~mL}$ of extracts or $\mathrm{FeSO}_{4}$ solution and $0.6 \mathrm{~mL}$ of distilled water were mixed and kept at $37{ }^{\circ} \mathrm{C}$ for $10 \mathrm{~min}$ before the absorbance was measured at $593 \mathrm{~nm}$. The result was expressed as $\mathrm{FeSO}_{4}$ equivalents.

\section{The colour determination}

The colour $\left(\mathrm{L}^{*}, \mathrm{a}^{*}\right.$ and $\mathrm{b}^{*}$ value) was characterised by Digi Eve digital electronic eye (Shanghai Eutin International Trading Co., Ltd.). A standard white and colour board were used to standardise the colorimeter, respectively.

\section{The micro-structures determination}

The internal morphology was investigated by scanning electron microscopy (SEM Hitachi S-570, Hitachi, Co., Ltd., Tokyo, Japan) at an acceleration voltage of $10 \mathrm{kV}$. The samples were frozen in liquid nitrogen and then sublimated rapidly to ensure that no water was presented in the samples. The samples were coated with sputtered gold before being photographed. The mung bean seeds and flour samples were observed at magnifications of $\times 500$ and $\times 1,000$, respectively.

\section{Thermal properties determination}

Thermal properties of samples were analysed using a differential scanning calorimeter (DSC-Q20, CT, USA). $3.5 \mathrm{mg}$ of mung bean flour was mixed with $7.0 \mathrm{mg}$ of deionised water in DSC-pans. It was then sealed and placed overnight at $4{ }^{\circ} \mathrm{C}$ for equilibration. The samples were analysed from 20 to $120{ }^{\circ} \mathrm{C}$ with the change in temperature of $10{ }^{\circ} \mathrm{C} / \mathrm{min}^{-1}$.

\section{Pasting properties determination}

The pasting properties of mung bean flour were investigated using Rapid Visco Analyzer (TechMaster, Perten, Sweden). Viscosity profiles of samples were recorded using flours suspensions $(4.5 \mathrm{~g}$ flour:20.0 $\mathrm{g}$ water, $\mathrm{w} / \mathrm{w})$. The temperature-time conditions included a heating step from 50 to $95{ }^{\circ} \mathrm{C}$ at $6{ }^{\circ} \mathrm{C} / \min ^{-1}$ after an equilibration time of $1 \mathrm{~min}$ at $50^{\circ} \mathrm{C}$, a holding phase at $95{ }^{\circ} \mathrm{C}$ for $5 \mathrm{~min}$, a cooling step from 95 to $50{ }^{\circ} \mathrm{C}$ at $6{ }^{\circ} \mathrm{C} / \mathrm{min}^{-1}$ and a holding phase at $50{ }^{\circ} \mathrm{C}$ for $2 \mathrm{~min}$.

Degree of starch gelatinisation determination during different cooking time

Cooking: native and $\mathrm{HRH}$-treated mung bean were boiled in water for different times (seeds:water $=50 \mathrm{~g}: 500 \mathrm{~g} \mathrm{w} / \mathrm{w}$; cooking time $15 \mathrm{~min}, 30 \mathrm{~min}$ and $45 \mathrm{~min}$, respectively). Then, the samples were freeze-dried, milled and sealed in plastic bags with some desiccant inside and stored at $4{ }^{\circ} \mathrm{C}$ for further analysis.

The degree of starch gelatinisation of cooked samples was measured by enzymatic determination (Liu \& Liu, 2020). Double $200 \mathrm{mg}$ of flour was weighed and put in two $25 \mathrm{~mL}$ tubes separately. Then, $15 \mathrm{~mL}$ of buffer solution (sodium acetate, $\mathrm{pH} 4.5$ ) was added to 
each tube. One tube was put in boiled water for $1 \mathrm{~h}$ to gelatinise totally, while another tube was put at room temperature to measure the degree of starch gelatinisation. Notably, the tube without flour was set as the blank. After that, $1.0 \mathrm{~mL}$ of enzyme solution (180 U amyloglucosidase ( $\mathrm{mL}$ ) was added and was incubated $1 \mathrm{~h}$ at $40{ }^{\circ} \mathrm{C}$ (shaking every $15 \mathrm{~min}$ ). Then, $2.0 \mathrm{~mL}$ of $10 \% \mathrm{ZnSO}_{4} .7 \mathrm{H}_{2} \mathrm{O}$ and $1.0 \mathrm{~mL}$ of $5 \mathrm{~N} \mathrm{NaOH}$ were mixed in the tube and made the volume reach to $25 \mathrm{~mL}$ with water. Then, $0.1 \mathrm{~mL}$ of above solution was mixed with $2 \mathrm{~mL}$ of copper reagents $(40 \mathrm{~g}$ $\mathrm{Na}_{2} \mathrm{CO}_{3}$ and $7.5 \mathrm{~g}$ tartaric acid were mixed in $400 \mathrm{~mL}$ distilled water, and $4.5 \mathrm{~g} \mathrm{CuSO}_{4} .5 \mathrm{H}_{2} \mathrm{O}$ was added to get $1000 \mathrm{~mL}$ with distilled water) in $25 \mathrm{~mL}$ tube. Then, the tube with sample solution was put in boiling water for $6 \mathrm{~min}$, and added $2.0 \mathrm{~mL}$ of phosphomolybdate reagents, and continued to boil for 2 min (phosphomolybdate reagents: $70 \mathrm{~g}$ molybdic acid and $10 \mathrm{~g}$ sodium tungstate were mixed with $400 \mathrm{~mL} 10 \%$ $\mathrm{NaOH}$ and $400 \mathrm{~mL}$ distilled water, after boiling for 20-40 min, the $\mathrm{NH}_{3}$ was expelled. After that, $700 \mathrm{~mL}$ distilled and $250 \mathrm{~mL} 85 \% \mathrm{H}_{3} \mathrm{PO}_{4}$ were added. Then the volume of mixed solution was adjusted to $1000 \mathrm{~mL}$ using distilled). Finally, the tube was cooled and diluted to $25 \mathrm{~mL}$. The absorbance was determined at $420 \mathrm{~nm}$. Degree of starch gelatinisation $(\%)=\left(\mathrm{A}_{1}\right.$. $\left.{ }_{1-} \mathrm{A}_{0}\right) \times 100 \% /\left(\mathrm{A}_{1-2}-\mathrm{A}_{0}\right)$, where $\mathrm{A}_{1-1}$ means the parboiling native or $\mathrm{HRH}$-treated mung bean flour; $\mathrm{A}_{1-2}$ means the completely gelatinised native or $\mathrm{HRH}-$ treated mung bean flour; $\mathrm{A}_{0}$ means the blank.

\section{Statistical analysis}

The data of the experiments were replicated three times. The statistical analysis was depended on the SPSS version 11.5. An analysis of the variance (ANOVA) test followed by Duncan Multiple Range Test was used for significant analysis. Data obtained from native and $\mathrm{HRH}$-mung bean were analysed using independent samples $t$ test. All significant differences were detected at $P<0.05$.

\section{Results and disscussing}

Optimisation for GABA accumulation in mung bean under HRH treatment using RSM.

The results of single-factor tests are presented in Supplement Fig. 2. The results showed that tempering moisture, $\mathrm{HRH}$ treatment temperature, $\mathrm{RH}$ and time had a significant influence $(P<0.05)$ on GABA accumulation according to one-way ANOVA analysis. Specifically, there was a gradual increase in GABA content with the increases of tempering moisture, but a sharp decrease occurred when tempering moisture exceeded 16\% (Supplement Fig. 2 A). The GABA content increased following the increases in processing temperature from 60 to $70{ }^{\circ} \mathrm{C}$, while the GABA content reduction was observed when the temperature was above $70{ }^{\circ} \mathrm{C}$ (Supplement Fig. $2 \mathrm{D}$ ). As shown in Supplement Fig. 2 E, the GABA content continuously increased with the increase of $\mathrm{RH}$. Considering the importance of moisture on GABA accumulation (Supplement Fig. 2 A), the highest relative humidity $(98 \%$ RH) was chosen, that's because the moisture must be lost with a low relative humidity. The GABA content continuously increased and reached the maximum level of $109.46 \mathrm{mg} 100 \mathrm{~g}^{-1} \mathrm{DW}$ at $5 \mathrm{~h}$ (Supplement Fig. 2 F). Therefore, tempering moisture (A, 12\%, 16\% and $20 \%$ ), HRH treatment temperature $\left(\mathrm{B}, 65^{\circ} \mathrm{C}, 70{ }^{\circ} \mathrm{C}\right.$ and $75^{\circ} \mathrm{C}$ ) and time $(\mathrm{C}, 4 \mathrm{~h}, 5 \mathrm{~h}$ and $6 \mathrm{~h}$ ) were selected as the key factors of Box-Behnken design (Table 1), and the analysis of variance (ANOVA) of the result of Box-Behnken was presented in Supplement Table. 1. The fitted quadratic mode for GABA (Y) of HRH-treated mung bean was estimated by RSM and was shown in Eq. (1).

The $p$-value of model $(0.0001)$ and $p$-value of lack of fit $(0.1255)$ proved that the model fits with the data and can be used to optimise the variables (Supplement Table. 1). Besides, the value of coefficient of determination $\left(\mathrm{R}^{2}\right)$ was 0.9728 , which indicated that $97.28 \%$ of the variation could be explained excellently (Supplement Table. 1). Based on RSM, HRH treatment temperature (B) and tempering moisture (A) significantly affected the GABA content of HRH-treated mung bean, followed by HRH treatment time $(\mathrm{C})$. The quadratic term $\left(\mathrm{A}^{2}, \mathrm{~B}^{2}\right.$ and $\left.\mathrm{C}^{2}\right)$ was significant $(P<0.05)$, and $\mathrm{AB}$ terms were also significant $(P<0.05)$. The other terms were insignificant.

The visual interaction between independent and dependent variables was clarified by three-dimensional response surface plots. The accumulation of GABA ranged from 69.98 to $112.28 \mathrm{mg} 100 \mathrm{~g} \mathrm{~g}^{-1} \mathrm{DW}$, which depended on the tempering moisture, $\mathrm{HRH}$ treatment temperature and time, and their interaction (Fig. 1 a-c).

Figure 1 (a) presented that the content of GABA was increased with the increase of tempering moisture and $\mathrm{HRH}$ treatment temperature within a certain range. Both of them exerted a significant effect on GABA accumulation ( $P$-value $=0.0181$ and 0.0013 respectively). The linear factor of their interaction also showed a significant influence on GABA accumulation $(P$-value $=0.0474)$. Figure $1(b)$ showed that the linear factor of HRH treatment time did not exert a significant influence on GABA content $(P$-value $=0.0734)$, and its interaction with tempering moisture also had no significant effect on GABA enhancement of mung bean, with a $P$-value of 0.6012 . From Fig. 1 (c), we can see that the GABA content increased with HRH treatment temperature to a certain value thereafter decreased. But the interaction of HRH treatment temperature and time showed no significant effect on GABA accumulation $(P$-value $=0.1716)$. 

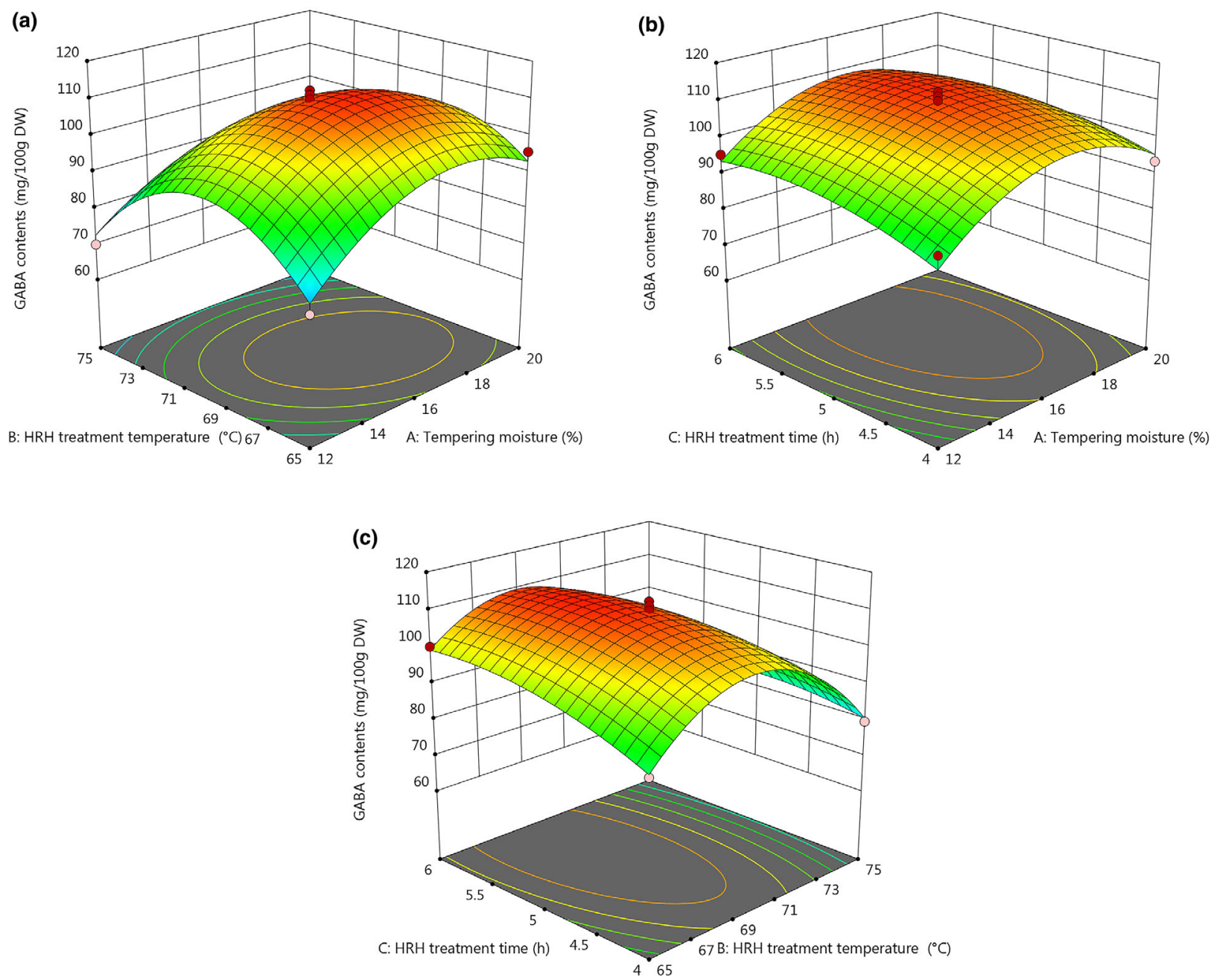

Figure 1 (a) Response surface for GABA accumulation in mung bean under HRH treatment. (b) Response surface for GABA accumulation in mung bean under HRH treatment (c) Response surface for GABA accumulation in mung bean under HRH treatment.

The GABA accumulation of mung bean under HRH treatment might be due to the residual ratelimiting enzymes GAD of GABA shunt and DAO of polyamine degradation pathway that got activated as result of HRH treatment (Yang et al., 2013). In previous studies, $45^{\circ} \mathrm{C}$ was an optimal temperature for GABA accumulation of adzuki bean during soaking and germination (Liao et al., 2013), while $40^{\circ} \mathrm{C}$ appeared optimal for GABA synthesis in rice bran with 30\% moisture contents (Kim et al., 2015). It suggested that the optimum generation temperature and moisture of GABA were different among various plants or treatment methods. In our study, the results suggested that for mung bean, GABA could be accumulated in an extremely low moisture content. Thus, HRH treatment was a promising approach to develop mung bean-based GABA-enriched functional foods.

\section{Verification of predictive models}

By prediction with computing program, the optimum conditions to produce the highest GABA content

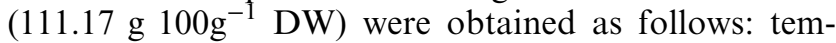
pering moisture of $16.72 \%, \mathrm{HRH}$ treatment temperature of $68.97{ }^{\circ} \mathrm{C}$ and $\mathrm{HRH}$ treatment time of $5.34 \mathrm{~h}$. Then, an experiment was carried out in triplicate under the optimal conditions. The result showed that

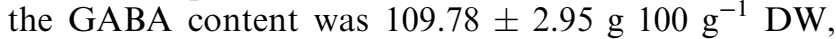
which was in good agreement with the predicted data.

\section{FAAs profiling}

As presented in Fig. 2, the Glu content (95.26 mg $\left.100 \mathrm{~g}^{-1} \mathrm{DW}\right)$ in native mung bean was the highest, followed by Arg (68.04 mg $\left.100 \mathrm{~g}^{-1} \mathrm{DW}\right)$ and 


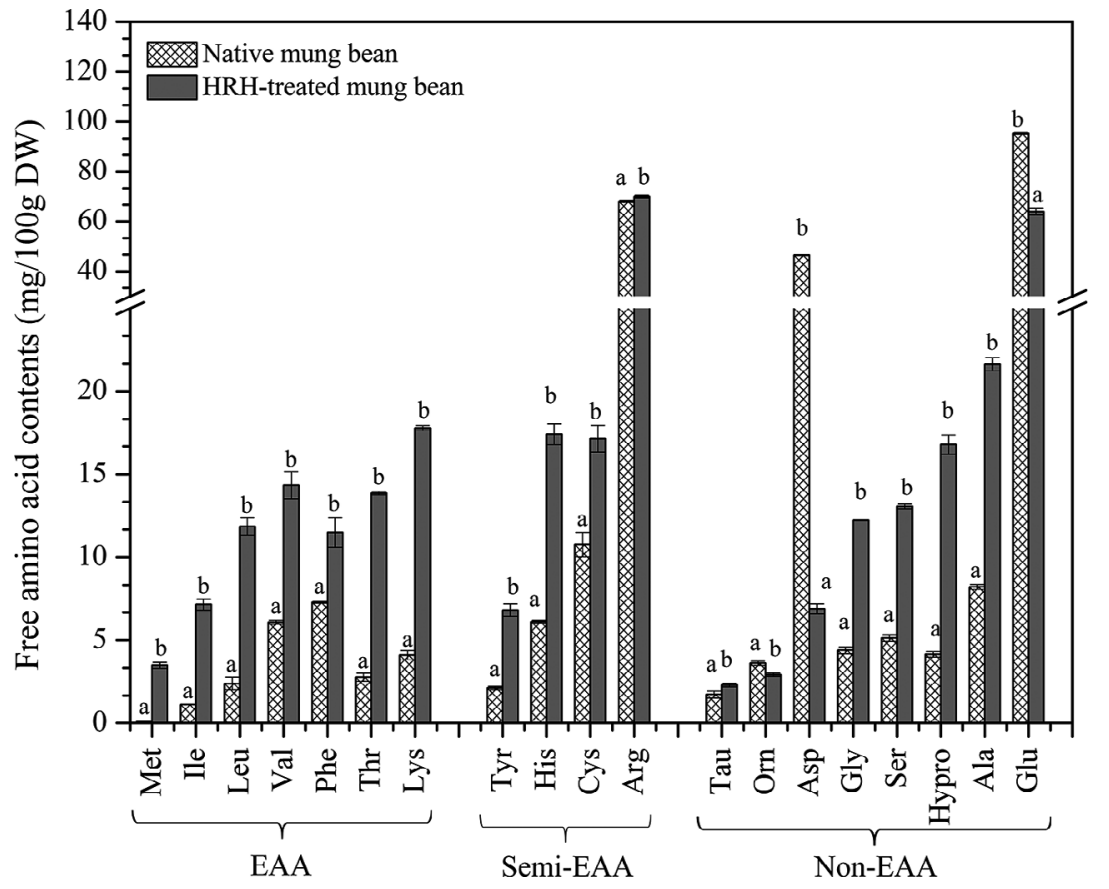

Figure 2 Free amino acid contents in native and HRH-treated mung bean.
Asp (46.50 mg $100 \mathrm{~g}^{-1} \mathrm{DW}$ ), which were in agreement with the previous study (Ali et al., 2016). However, HRH treatment not only changed the profiles of FAAs in mung bean, but also significantly increased the total amount of FAAs (from 279.86 to $331.18 \mathrm{mg} 100 \mathrm{~g}^{-1}$ DW). Overall, except for Non-EAAs, including Glu, Asp and Orn, showed a significant decrease $(P<0.05)$, and all other FAAs had a significant increase $(P<0.05)$. Among them, the amounts of Met, Ile and Thr increased more than 5 times, and those of Leu, Lys, Hypro and Tyr increased 3-5 times. Especially, the contents of sulphur-containing amino acids, including Met and Cys, increased from 0.10 to 3.49 and 10.76 to $17.15 \mathrm{mg} 100 \mathrm{~g}^{-1} \mathrm{DW}$, respectively. The aromatic amino acids, including Tyr and Phe, increased from 2.11 to 6.81 and 7.28 to $11.49 \mathrm{mg} 100 \mathrm{~g}^{-1} \mathrm{DW}$, respectively, and the branchedchain amino acids, including Leu, Ile and Val, also augmented from 1.13 to $7.15,2.38$ to 11.85 and 6.09 to $14.34 \mathrm{mg} 100 \mathrm{~g}^{-1} \mathrm{DW}$, respectively. A similar tendency to the changes of FAAs was also found in germinated brown rice under soaking and gaseous treatment (Komatsuzaki et al., 2007).

Normally, the seeds are dormant, but they can be activated in suitable conditions, such as germination. Under HRH treatment, the mung bean absorbed water and situated in a low oxygen and high-temperature environment, which also made it possible to induce various biological reaction by activating various residual enzymes. Kim et al. (2015) also found similar changes in FAAs in rice bran treated by an anaerobic storage. It has been reported that Glu and Asp were direct or indirect precursor of GABA and other FAAs, and Glu-to- $\alpha$-ketoglutarate conversion is used to provide an amino group in various transamination reactions which allow conversion of Glu and Asp to Met, Thr, Ile and Lys by the plastidial asparatate-family pathway (Fait et al., 2008; Podlešáková et al., 2019). Therefore, we speculated that the increase of other FAAs was related to the consumption of Asp and Glu. However, the transformation among FAAs of mung bean under HRH treatment is still not entirely clear. In view of the antioxidant properties of aromatic and sulphur-containing amino acids, and the important role of branched-chain amino acid on skeletal muscle and liver (Plate 11 et al., 2000; Garzón \& Drago, 2018), the approach was valuable in manipulating the FAAs profiles and improving the functional amino acid compounds of mung bean.

\section{Phytochemical compounds and antioxidant activities}

As shown in Table 2, the contents of TPC, TAC, vitexin and isovitexin of mung bean were 2.06, 1.74, 2.11 and $1.20 \mathrm{mg} \mathrm{g}^{-1} \mathrm{DW}$, respectively, which were similar to the report of Yao et al. (2011). After HRH treatment, the contents of TPC, vitexin and isovitexin in mung bean increased significantly $(P<0.05)$, while the content of TAC decreased significantly $(P<0.05)$. However, the values of FRAP, DPPH and ABTS free radicals scavenging activity of mung bean showed a significant increase $(P<0.05)$. The decreases in the 
Table 2 Phytochemical components and antioxidant activities of native and $\mathrm{HRH}$-treated mung bean

\begin{tabular}{lll}
\hline & $\begin{array}{l}\text { Native mung } \\
\text { bean }\end{array}$ & $\begin{array}{l}\text { HRH-treated mung } \\
\text { bean }\end{array}$ \\
\hline $\begin{array}{l}\text { Phytochemical } \\
\text { components }\end{array}$ & \\
TPC mg/g DW & & \\
TAC mg/g DW & $2.06 \pm 0.12 \mathrm{~b}$ & $2.49 \pm 0.19 \mathrm{a}$ \\
Vitexin mg/g DW & $1.74 \pm 0.06 \mathrm{a}$ & $0.93 \pm 0.11 \mathrm{~b}$ \\
Isovitexin mg/g DW & $2.11 \pm 0.10 \mathrm{~b}$ & $2.46 \pm 0.16 \mathrm{a}$ \\
Antioxidant activities & $1.20 \pm 0.05 \mathrm{~b}$ & $1.40 \pm 0.04 \mathrm{a}$ \\
DPPH $\mu \mathrm{M} / \mathrm{g}$ DW & $28.88 \pm 0.57 \mathrm{~b}$ & $32.72 \pm 0.53 \mathrm{a}$ \\
ABTS $\mu \mathrm{M} / \mathrm{g}$ DW & $16.15 \pm 0.40 \mathrm{~b}$ & $17.44 \pm 0.63 \mathrm{a}$ \\
FRAP $\mu \mathrm{M} / \mathrm{g}$ DW & $14.76 \pm 0.82 \mathrm{~b}$ & $18.49 \pm 0.73 \mathrm{a}$ \\
\hline
\end{tabular}

TPC, (total phenolic content), TAC (total anthocyanins content), DPPH (1,1-diphenyl-2-picrylhydrazyl), ABTS (2,2'-azino-bis 3

ethylbenzothiazoline-6-sulphonic acid) FRAP (ferric reducing antioxidant power). Results are the mean of three samples \pm standard deviation. Different letters in the same row represent significant differences between native mung bean and $\mathrm{HRH}$-treated mung bean $(p<0.05)$. Same as follows.

TAC content of mung bean under HRH treatment should be attributed to its thermolability. The increases in TPC content and antioxidant activities of mung bean under HRH treatment are possibly due to the activation of related enzymatic involved in the biosynthesis of phenolic compounds, such as esterase and phenylalanine-ammonialyase (Perales-Sánchez et al., 2014; Gómez-Favela et al., 2017). Similarly, results were also found in soaked barley (Al-Ansi et al., 2020). Besides, Garzón \& Drago (2018) reported that some FAAs had a positive correlation with antioxidant activities, especially aromatic and sulphurcontaining amino acids. In this study, the contents of aromatic and sulphur-containing amino acids of HRH-treated mung bean were higher than native mung bean (Fig. 2).

\section{Particle morphology, micro-structure and colour}

Result showed that the particle morphology of HRHtreated mung bean seeds is consistent with native mung bean seeds, while the glossiness was a little weak (Supplement Fig. 3 a and b), which may be due to the damage of waxy structure of mung bean seeds surface under $\mathrm{HRH}$ treatment. Besides, the surface of the mung bean seeds had a little shrinkage because of water absorption and drying processing. From the perspective of appearance (Supplement Fig. $3 \mathrm{c}$ and d) and micro-structure (Supplement Fig. $3 \mathrm{~g}$ and h) of mung bean flour, HRH treatment almost had no influence on them. However, the micro-structure of mung bean seeds was changed greatly under HRH treatment
(Supplement Fig. 3 e and f). The starch granules in native mung bean seeds cells were clear and uniform, but were almost invisible after HRH treatment, which reflected that partial starch was gelled and wrapped other starch after treatment. Huang et al. (2016) also found the partial gelatinisation of the sweet potato starch during heat-moisture treatment and the degree of gelatinisation increased with the processing time.

Supplement Fig. 4 showed that HRH-treated mung bean seeds had higher $\mathrm{L}^{*}$ and $\mathrm{a}^{*}$ than native for the seeds. It might be due to the degradation of anthocyanins (Castañeda-Ovando et al., 2009) or the loss of water-soluble pigments. For HRH-treated mung bean flour, it showed a lower value of $\mathrm{L}^{*}, \mathrm{a}^{*}$ and $\mathrm{b}^{*}$ than native mung bean flour. It might be attributed to the transformation of pigments from the seed coat to the endosperm layer or maillard reaction (Lamberts et al., 2008).

\section{Thermal and pasting properties}

In order to better understand the processing properties of HRH-treated mung bean flour, the thermal and pasting properties were summarised in Table 3 and Supplement Fig. 5. In terms of thermal properties, HRH treatment significantly increased $(P<0.05)$ the value of $\mathrm{T}_{0}$ of mung bean flour, which indicated that partial starch in mung bean flour was gelatinised during the processing of $\mathrm{HRH}$ treatment. The results were in accordance with the results of SEM (Supplement Fig. 3 e and $f$ ). The reason for the increase of $T_{0}$ should be attributed to the preferential melting of less stable crystallites of starch in mung bean flour, leaving behind more stable residual crystallites with a higher melting temperature (Wang et al., 2016).

From the perspective of pasting properties, except for PT, HRH treatment resulted in a significant increase $(P<0.05)$ in all other parameters of mung bean flour including PV, TV, FV, SBV, BDV and Pt. Similar results were observed in the high hydrostatic pressure-treated mung bean starches (Li et al., 2011b). These alterations in viscosity and $\mathrm{Pt}$ following the $\mathrm{HRH}$ treatment might result from the changes of granular structures during the transformation and reorganisation of crystalline structure (Katopo et al., 2002; Li et al., 2011a). The significant increase $(P<0.05)$ of viscosity of HRH-treated mung bean flour was demonstrated to produce a more viscous paste than native mung bean flour. The higher SBV was observed in the HRH-treated mung bean flour, suggesting their higher tendency towards retrogradation. Li et al. (2012) reported that better quality of noodles required high viscosity of flour. The gelatinisation and retrogradation of starchy flour played a vital role on the 'rigid' structure of gluten-free pasta (Marti \& Pagani, 2013). Therefore, the positive effect of $\mathrm{HRH}$ treatment on 


\begin{tabular}{lcc}
\hline & Native mung bean & HRH-treated mung bean \\
\hline Thermal properties & & \\
$\mathrm{T}_{0}\left({ }^{\circ} \mathrm{C}\right)$ & $62.57 \pm 0.26 \mathrm{~b}$ & $65.04 \pm 0.44 \mathrm{a}$ \\
$\mathrm{T}_{\mathrm{p}}\left({ }^{\circ} \mathrm{C}\right)$ & $72.52 \pm 0.42$ & $72.09 \pm 0.01$ \\
$\Delta \mathrm{H}(\mathrm{J} / \mathrm{g})$ & $2.95 \pm 0.27$ & $3.44 \pm 0.24$ \\
Pasting properties & & \\
$\mathrm{PV}(\mathrm{cp})$ & $2844 \pm 99 \mathrm{~b}$ & $4115 \pm 25 \mathrm{a}$ \\
$\mathrm{TV}(\mathrm{cp})$ & $1592 \pm 23 \mathrm{~b}$ & $2536 \pm 25 \mathrm{a}$ \\
$\mathrm{FV}(\mathrm{cp})$ & $2907 \pm 47 \mathrm{~b}$ & $4836 \pm 37 \mathrm{a}$ \\
$\mathrm{BDV}(\mathrm{cp})$ & $1251 \pm 77 \mathrm{~b}$ & $1579 \pm 20 \mathrm{a}$ \\
$\mathrm{SBV}(\mathrm{cp})$ & $1315 \pm 24 \mathrm{~b}$ & $2301 \pm 39 \mathrm{a}$ \\
$\mathrm{Pt}(\mathrm{min})$ & $7.75 \pm 0.04 \mathrm{~b}$ & $8.58 \pm 0.08 \mathrm{a}$ \\
$\mathrm{PT}\left({ }^{\circ} \mathrm{C}\right)$ & $72.62 \pm 0.23$ & $72.73 \pm 0.03$ \\
\hline
\end{tabular}

$T_{0}$ (Onset temperature), $T_{p}$ (endothermic peak temperature), $\Delta H$, (gelatinisation enthalpy), $P V$, (peak viscosity), TV (trough viscosity), (FV) final viscosity, BDV (breakdown viscosity), SBV (setback viscosity), Pt (peak time), PT (pasting temperature).

pasting properties should be concerned. However, the quality characteristics of HRH-treated mung beancorrelated products need further research.

\section{The degree of starch gelatinisation of mung bean under} different cooking time

It is well known that mung bean needs longer time to cook thoroughly in the boiling water than cereals, which limited their consumption and application to some extent. Figure 3 has shown that the starch gelatinisation degrees of native and $\mathrm{HRH}$-treated mung bean seeds were increased with the increasing cooking
Table 3 Thermal and pasting properties of native and $\mathrm{HRH}$-treated mung bean flour

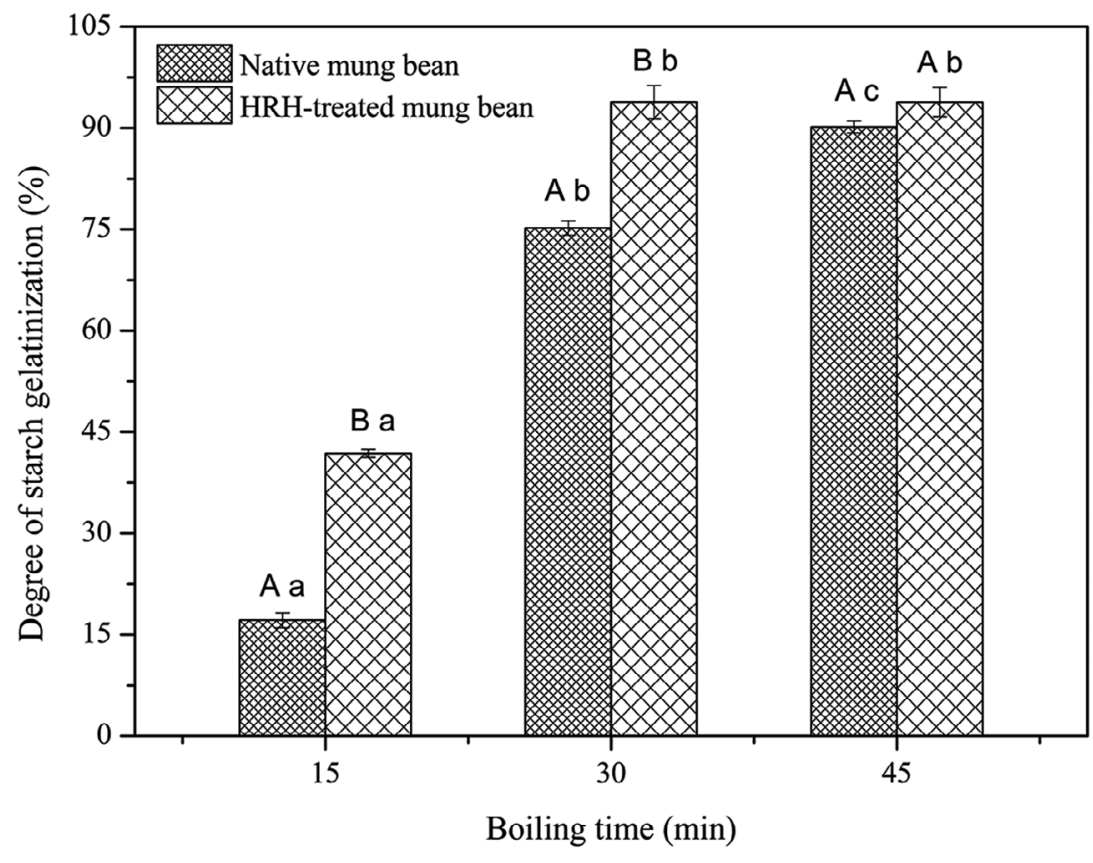

International Journal of Food Science and Technology 2022 time. Besides, the starch gelatinisation degree of $\mathrm{HRH}$ treated mung bean was significantly higher $(P<0.05)$ than native mung bean within $30 \mathrm{~min}$. However, there were no significant differences in the starch gelatinisation degrees of $\mathrm{HRH}$-treated mung bean with $30 \mathrm{~min}$ and $45 \mathrm{~min}$ boiling time. Briefly, the HRH-treated mung bean is easier to cook thoroughly than native mung bean, and the cooking time would be shortened by $15 \mathrm{~min}$. On the one hand, as we described above (3.5), mung bean starch has been partially gelatinised in advance under HRH treatment. Therefore, less starch in HRH-treated mung bean needed to be gelatinised during cooking. On the other hand, the dense
Figure 3 Starch gelatinization degree of native and HRH-treated mung bean under different boiling time. 
structure of mung bean coat was destroyed under HRH treatment Supplement Fig. 3 b), which made it easier to absorb water and provided sufficient moisture for starch gelatinisation quickly.

\section{Conclusion}

The GABA content of mung bean was more than 60 times higher than that of native mung bean (from 1.73

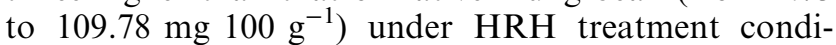
tions (tempering: $16.72 \%$ moisture, $25{ }^{\circ} \mathrm{C}, 5 \mathrm{~h} ; \mathrm{HRH}$ treatment: $98 \% \mathrm{RH}, 68.97{ }^{\circ} \mathrm{C}$ for $5.34 \mathrm{~h}$ ). Meanwhile, the contents of some FAAs in mung bean, such as aromatic (Tyr and Phe), sulphur-containing (Cys) and branched-chain amino acids (Leu and Leu), were significantly increased $(P<0.05)$ under HRH treatment, while Non-EAA (Glu, Arg and Asp) was significantly decreased $(P<0.05)$. Besides, although the content of TAC in mung bean had a significant decrease $(P<0.05)$ after HRH treatment, the TPC, vitexin and isovitexin contents and antioxidant activities had a significant increase $(P<0.05)$. In terms of physicochemical properties, HRH treatment did not change the particle morphology of mung bean, but caused the wrinkled structure of mung bean coat, significantly changed its internal micro-structure and increased pasting viscosity, which eventually caused the cooking time of HRH-treated mung bean was shortened by 15 min compared with native mung bean. Our results provide a comprehensive understanding of $\mathrm{HRH}$ treated mung bean and will be useful in promoting its consumption, especially for chronic patients and consumers with a fast-paced life.

\section{Acknowledgments}

The authors would like to thank Houqing Liu for his technical assistance on heat and relative humidity treatment. This work was supported by the Special Fund for Modern Agricultural Industrial Technology System (CARS-08-G19).

\section{Author Contribution}

Yuling Ma: Investigation (lead); Software (lead); Writing-original draft (lead); Writing-review \& editing (lead). Li-Tao Tong: Data curation (lead). Shanshan Wang: Formal analysis (lead). Tingyu Liu: Methodology (lead). Lili Wang: Visualization (lead). Liya Liu: Writing-review \& editing (equal). Xianrong Zhou: Project administration (equal). Sumei Zhou: Conceptualization (lead); Funding acquisition (lead); Project administration (lead); Resources (lead); Supervision (lead); Writingreview \& editing (equal). Christophe Blecker: Project administration (equal); Supervision (equal); Validation (equal); Writing-review \& editing (equal).

\section{Ethical Guidelines.}

Ethics approval was not required for this research.

\section{Conflict of interest.}

The authors declare no conflict of interest.

\section{Peer review}

The peer review history for this article is available at https://publons.com/publon/10.1111/ijfs.15455.

\section{Data availability.}

Research data are not shared.

\section{References}

Al-Ansi, W., Mahdi, A.A., Al-Maqtari, Q.A. et al. (2020). The potential improvements of naked barley pretreatments on GABA, $\beta$-glucan, and antioxidant properties. LWT- Food Science and Technology, 130, 109698.https://doi.org/10.1016/j.lwt.2020.109698.

We cited this reference to compare the result of GABA and total phenolic acid content in soaked barley with our results.

Ali, N.M., Yeap, S.K., Yusof, H.M. et al. (2016). Comparison of free amino acids, antioxidants, soluble phenolic acids, cytotoxicity and immunomodulation of fermented mung bean and soybean. Journal of the Science of Food \& Agriculture, 96(5), 1648-1658. https://doi.org/10.1002/jsfa.7267.

We cited this reference to compare the result of free amino acids in native mung bean and GABA content in fermented mung bean with our results.

Castañeda-Ovando, A., Pacheco-Hernández, M.L., Páez-Hernández, M.E., Rodríguez, J.A. \& Galán-Vidal, C.A. (2009). Chemical studies of anthocyanins: A review. Food Chemistry, 113(4), 859-871. https://doi.org/10.1016/j.foodchem.2008.09.001.

We cited this reference to know the properties of anthocyanins and explain the reason of the their degradation.

Chen, Y., Zhang, H., Wang, Y.X., Nie, S.P., Li, C. \& Xie, M.Y. (2014). Acetylation and carboxymethylation of the polysaccharide from Ganoderma atrum and their antioxidant and immunomodulating activities. Food Chemistry, 156, 279-288. https://doi.org/10. 1016/j.foodchem.2014.01.111.

Chua, J.Y., Koh, M.K.P. \& Liu, S.Q. (2019). 2 - Gammaaminobutyric acid: A bioactive compound in foods. Sprouted Grains, 25-54. https://doi.org/10.1016/B978-0-12-811525-1.00002-6.

Diez-Gutiérrez, L., San Vicente, L., R. Barrón, L. J., Villarán, M. D. C. \& Chávarri, M.. (2020). Gamma-aminobutyric acid and probiotics: Multiple health benefits and their future in the global functional food and nutraceuticals market. Journal of Functional Foods, 64, 103669-https://doi.org/10.1016/j.jff.2019.103669.

Fait, A., Fromm, H., Walter, D., Galili, G. \& Fernie, A.R. (2008). Highway or byway: the metabolic role of the GABA shunt in plants. Trends in Plant Science, 13(1), 14-19. https://doi.org/10. 1016/j.tplants.2007.10.005.

Fukumori, T., Kanemoto, S., Mizuno, H., Wakabayashi, K., Liu, H.Q. \& Ochiai, S. (2013). Grain or legume having increased content of functional component and a manufacturing method thereof. US8399037B2.

Ganesan, K. \& Xu, B.J. (2018). A critical review on phytochemical profile and health promoting effects of mung bean ( Vigna radiata ). Food Science and Human Wellness, 7(1), 11-33. https://doi.org/ 10.1016/j.fshw.2017.11.002. 
Garzón, A.G. \& Drago, S.R. (2018). Free $\alpha$-amino acids, $\gamma$ Aminobutyric acid (GABA), phenolic compounds and their relationships with antioxidant properties of sorghum malted in different conditions. Journal of Food Science \& Technology, 55(8), 31883198. https://doi.org/10.1007/s13197-018-3249-0.

Gómez-Favela, M.A., Gutiérrez-Dorado, R., Cuevas-Rodríguez, E.O. et al. (2017). Improvement of chia seeds with antioxidant activity, GABA, essential amino acids, and dietary fiber by controlled germination bioprocess. Plant Foods for Human Nutrition, 72(4), 345-352. https://doi.org/10.1007/s11130-017-0631-4.

Hosseinian, F.S., Li, W. \& Beta, T. (2008). Measurement of anthocyanins and other phytochemicals in purple wheat. Food Chemistry, 109(4), 916-924. https://doi.org/10.1016/j.foodchem.2007.12. 083.

Huang, T.T., Zhou, D.N., Jin, Z.Y., Xu, X.M. \& Chen, H.Q. (2016). Effect of repeated heat-moisture treatments on digestibility, physicochemical and structural properties of sweet potato starch. Food Hydrocolloids, 54, 202-210. https://doi.org/10.1016/j.foodhyd. 2015.10.002.

Katopo, H., Song, Y. \& Jane, J.-L. (2002). Effect and mechanism of ultrahigh hydrostatic pressure on the structure and properties of starches. Carbohydrate Polymers, 47(3), 233-244. https://doi.org/10. 1016/S0144-8617(01)00168-0.

Kim, H.S., Lee, E.J., Lim, S.-T. \& Han, J.-A. (2015). Selfenhancement of GABA in rice bran using various stress treatments. Food Chemistry, 172, 657-662. https://doi.org/10.1016/j. foodchem.2014.09.107.

We cited this reference to compare the method of self-enhancement of GABA and the result of GABA content in rice bran with our results of GABA accumulation.

Komatsuzaki, N., Tsukahara, K., Toyoshima, H., Suzuki, T., Shimizu, N. \& Kimura, T. (2007). Effect of soaking and gaseous treatment on GABA content in germinated brown rice. Journal of Food Engineering, 78(2), 556-560. https://doi.org/10.1016/j.jfoodeng.2005. 10.036 .

Lamberts, L., Rombouts, I., Brijs, K., Gebruers, K. \& Delcour, J.A. (2008). Impact of parboiling conditions on Maillard precursors and indicators in long-grain rice cultivars. Food Chemistry, 110(4), 916-922. https://doi.org/10.1016/j.foodchem.2008.02.080.

Li, M., Zhu, K.X., Wang, B.W., Guo, X.N., Peng, W. \& Zhou, H.M. (2012). Evaluation the quality characteristics of wheat flour and shelf-life of fresh noodles as affected by ozone treatment. Food Chemistry, 135(4), 2163-2169. https://doi.org/10.1016/j.foodchem. 2012.06.103.

Li, S., Ward, R. \& Gao, Q. (2011a). Effect of heat-moisture treatment on the formation and properties of resistant starches from mung bean (Phaseolus radiatus) starch. Food Hydrocolloids, 25, 1702-1709. https://doi.org/10.1016/j.foodhyd.2011.03.009.

Li, W., Zhang, F., Liu, P., Bai, Y., Gao, L. \& Shen, Q. (2011b). Effect of high hydrostatic pressure on physicochemical, thermal and morphological properties of mung bean (Vigna radiata $\mathrm{L}$.) starch. Journal of Food Engineering, 103(4), 388-393. https://doi. org $/ 10.1016 /$ j.jfoodeng. 2010.11 .008 .

Liang, S., Su, C., Saleh, A.S.M. et al. (2020). Repeated and continuous dry heat treatments induce changes in physicochemical and digestive properties of mung bean starch. Journal of Food Processing and Preservation, 45, e15281. https://doi.org/10.1111/jfpp. 15281 .

Liao, W.C., Wang, C.Y., Shyu, Y.T., Yu, R.C. \& Ho, K.C. (2013). Influence of preprocessing methods and fermentation of adzuki beans on $\gamma$-aminobutyric acid (GABA) accumulation by lactic acid bacteria. Journal of Functional Foods, 5(3), 1108-1115. https://doi. org/10.1016/j.jff.2013.03.006.

Liu, K. \& Liu, Q. (2020). Enzymatic determination of total starch and degree of starch gelatinization in various products. Food Hydrocolloids, 103, 105639. https://doi.org/10.1016/j.foodhyd.2019. 105639.
Liu, Y., Xu, M., Wu, H. et al. (2018). The compositional, physicochemical and functional properties of germinated mung bean flour and its addition on quality of wheat flour noodle. Journal of Food Science \& Technology, 55(12), 5142-5152. https://doi.org/10.1007/ s13197-018-3460-z.

Ma, Y., Tong, L., Li, J. et al. (2021). Comparison of $\gamma$-aminobutyric acid accumulation capability in different mung bean (Vigna radiata L.) varieties under heat and relative humidity treatment, and its correlation with endogenous amino acids and polyamines. International Journal of Food Science \& Technology, 56, 1562-1573.

Marti, A. \& Pagani, M.A. (2013). What can play the role of gluten in gluten free pasta? Trends in Food Science \& Technology, 31(1), 63-71. https://doi.org/10.1016/j.tifs.2013.03.001.

Nikmaram, N., Dar, B.N., Roohinejad, S. et al. (2017). Recent advances in $\gamma$-aminobutyric acid (GABA) properties in pulses: an overview. Journal of the Science of Food and Agriculture, 97, 26812689.

Perales-Sánchez, J.X.K., Reyes-Moreno, C., Gómez-Favela, M.A. et al. (2014). Increasing the antioxidant activity, total phenolic and flavonoid contents by optimizing the germination conditions of amaranth seeds. Plant Foods for Human Nutrition, 69(3), 196-202. https://doi.org/10.1007/s11130-014-0430-0.

Platell, C., Kong, S.-E., Mccauley, R. \& Hall, J.C. (2000). Branchedchain amino acids. Journal of Gastroenterology and Hepatology, 15 (7), 706-717. https://doi.org/10.1046/j.1440-1746.2000.02205.x.

Podlešáková, K., Ugena, L., Spíchal, L., Doležal, K. \& Diego, N.D. (2019). Phytohormones and polyamines regulate plant stress responses by altering GABA pathway. New Biotechnology, 48, 5365. https://doi.org/10.1016/j.nbt.2018.07.003.

Wang, S., Zhang, X., Wang, S. \& Copeland, L. (2016). Changes of multi-scale structure during mimicked DSC heating reveal the nature of starch gelatinization. Scientific Reports, 6(1), 28271. https:// doi.org/10.1038/srep28271.

Wu, H., Rui, X., Li, W., Chen, X., Jiang, M. \& Dong, M. (2015). Mung bean (Vigna radiata) as probiotic food through fermentation with Lactobacillus plantarum B1-6. LWT - Food Science and Technology, 63, 445-451. https://doi.org/10.1016/j.lwt.2015.03.011.

Yang, R.Q., Guo, Q.H. \& Gu, Z.X. (2013). GABA shunt and polyamine degradation pathway on $\gamma$-aminobutyric acid accumulation in germinating fava bean (Vicia faba L.) under hypoxia. Food Chemistry, 136, 152-159. https://doi.org/10.1016/j.foodchem.2012.08.008.

Yao, Y., Chen, X. Z. \& Ren, G. X (2011). Contents of D-chiroinositol, vitexin, and isovitexin in various varieties of mung bean and its products. Agricultural Sciences in China, 10, 1710-1715. https://doi.org/10.1016/S1671-2927(11)60169-7.

Yao, Y., Sang, W., Zhou, M. J. \& Ren, G. X. (2010). Phenolic composition and antioxidant activities of 11 celery cultivars. Journal of Food Science, 75, C9-C13. https://doi.org/10.1111/j.1750-3841. 2009.01392.x.

Zhao, G. C., Xie, M. X., Wang, Y. C. \& Li, J. Y. (2017). Molecular mechanisms underlying $\gamma$-aminobutyric acid (GABA) accumulation in giant embryo rice seeds. Journal of Agricultural and Food Chemistry, 65, 4883-4889. https://doi.org/10.1021/acs.jafc.7b00013.

Zhu, Y. S., Sun, S. \& Richard, F.G. (2018). Mung bean proteins and peptides: nutritional, functional and bioactive properties. Food \& Nutrition Research, 62, 1290. https://doi.org/10.29219/fnr.v62. 1290 .

\section{Supporting Information}

Additional Supporting Information may be found in the online version of this article:

Supplementary Material 